\title{
Desempenho Animal e Avaliação do Potencial Produtivo de Forragens para Ensilagem, por Intermédio de Diferentes Fontes de Suplementação Nitrogenada
}

\author{
José Marques da Silva ${ }^{1}$, Gelson Luis Dias Feijó ${ }^{2}$, Luiz Roberto Lopes de S. Thiago ${ }^{3}$, Armindo \\ Neivo Kichel ${ }^{4}$, João Cândido Abella Porto ${ }^{5}$
}

\begin{abstract}
RESUMO - Este estudo foi conduzido para avaliar o milho (Zea mays L.) AG 1051 e os sorgos (Sorghum bicolor, (L.) Moench) AG 2006 e BR 303, para produção de silagem, e verificar o efeito da substituição do farelo de soja por uréia ( 0,50 e $100 \%)$, nas rações concentradas para bovinos confinados. As silagens foram usadas em dois experimentos e os animais foram distribuídos em delineamento experimental inteiramente casualizado. No primeiro, 72 bovinos mestiços F1 Pardo Suíço x Nelore, inteiros, com 20 meses de idade e 412 kg PV, foram distribuídos em arranjo fatorial 3 x 3 (silagem de milho e de sorgos e nível de substituição do farelo de soja por uréia). No segundo, 48 novilhos Nelore, com 34 meses e $378 \mathrm{~kg}$ PV, foram distribuídos em arranjo fatorial 2 x 3 (silagem de sorgos e nível de substituição do farelo de soja por uréia). Não houve diferença entre as forragens quanto às produções/ha de matéria seca total e de folha, colmo e à relação espiga/panícula. As plantas de milho e sorgo BR 303 apresentaram cerca de 53\% de espiga/panícula quando comparado a 45\% do sorgo AG 2006 . Não houve interação entre as silagens e a fonte de nitrogênio. A silagem de milho propiciou melhor desempenho para os animais mestiços. Economicamente, o melhor resultado foi obtido com o uso da silagem de milho e do farelo de soja. O desempenho dos animais Nelores não foi influenciado pelo tipo de silagem e pela fonte de nitrogênio. Não houve diferença no retorno econômico para as silagens. Contudo, para as fontes de nitrogênio, o maior retorno economico foi obtido com o uso da uréia, seguido da mistura farelo de soja + uréia e, por último, com o farelo de soja.
\end{abstract}

Palavras-chave: bovino de corte, confinamento, cruzamento, farelo de soja, forragem, milho, Nelore, silagem, sorgo, uréia

\section{Animal Performance and Evaluation of Forage Potential Production for Silage Making by Means of Different Sources of Nitrogen Supplementation}

\begin{abstract}
This study was conducted to evaluate the corn (Zea mays L.) AG 1051 and the sorghums (Sorghum bicolor (L.) Moench) AG 2006 and BR 303, for silage production, and the effect of substitution of soybean meal by urea (0,50 and $100 \%)$ in the concentrated diets for feedlot cattle. The silages were used in two experiments and the animals were alloted to a completely experimental design. In the first, $72 \mathrm{~F} 1$ crossbred Brown Swiss x Nellore bulls, with 20 months of age and $412 \mathrm{~kg}$ LW were distributed to a $3 \times 3$ factorial arrangement (corn silage and sorghums silage and level of substitution of soybean meal by urea). In the second, 48 Nellore steers, with 34 month of age and $378 \mathrm{~kg} \mathrm{LW}$, were allotted to a 2 x 3 factorial arrangement (sorghum silage and level of substitution of soybean by urea). There were no differences between the forages as for production/ha of total dry matter and leaves, stem and of ear/panicle ratio. The corn and sorghum BR 303 plants presented about $53 \%$ of ear/panicle ratio as compared to $45 \%$ of the sorghum AG 2006 . There was no interaction between the silage and the nitrogen source. The corn silage provided better performance for the crossbred bulls. Economically, the highest profit was obtained by using corn silage and soybean meal. The performance of Nellore steers was not affected by silage type or nitrogen source. There were no differences in the economic return for the silages. However, for the nitrogen source, the higher economic return was obtained by the use of urea followed by soybean meal + urea mixture and, finally, by soybean meal.
\end{abstract}

Key Words: beef cattle, feedlot, crossbred, soybean meal, forage, corn, Nellore, silage, sorghum, urea

\section{Introdução}

$\mathrm{Na}$ produção de gado de corte tem se tornado cada vez mais comum a prática da confecção de silagem. Isto tem acontecido, segundo DEMARCHI et al. (1995), principalmente em regiões com exploração pecuária mais tecnificada, em que a procura por melhores índices zootécnicos e rentabilidade econômica tem levado grande número de produtores que utilizam o confinamento a adotarem sistematicamente esta prática. Outro fator que tem contribuído para o aumento da ensilagem é a integração agricultura/ pecuária, pois é cada vez maior o número de agricultores que têm utilizado pastagem em sistema de

1 Eng.-Agr., M.Sc., CREA No 11938/D-Visto 1302/MS, da Embrapa Gado de Corte.

2 Méd.-Vet., Ph.D., CRMV-MS No 1472, da Embrapa Gado de Corte.

3 Eng.-Agr., Ph.D., CREA No 852/D-Visto 1522/MS, da Embrapa Gado de Corte.

${ }^{4}$ Eng.-Agr., M.Sc., CREA No 37391/D, da Embrapa Gado de Corte.

${ }^{5}$ Méd.-Vet., M.Sc., CRMV-MS No 0187, da Embrapa Gado de Corte. 
rotação com culturas anuais, além de ter crescido o número de pecuaristas que têm utilizado a agricultura como forma de reduzir o custo de recuperação ou renovação de pastagens.

De acordo com COUTINHO FILHO et al. (1987), ao contrário dos países desenvolvidos, a relação preço de grão/preço da carne bovina no Brasil, por várias razões, é desvantajosa. Este fato tem tornado a ensilagem uma prática interessante, pois permite obtenção de 30 a $50 \%$ a mais de nutrientes em relação à produção de grãos (PERRY e CECAVA, 1995).

O lançamento de novos cultivares de milho e sorgo também tem estimulado a produção de silagem. Segundo NUSSIO (1993), híbridos mais produtivos e adaptados às condições locais têm sido apontados por produtores e técnicos como responsáveis por ganhos efetivos em produtividade.

O milho e o sorgo são culturas mais adaptadas ao processo de ensilagem, por sua facilidade de cultivo, altos rendimentos e, especialmente, pela qualidade da silagem produzida sem o uso de aditivos ou prémurchamento (DEMARCHI et al., 1995). O milho é a cultura mais indicada para locais de solos mais férteis e clima mais favorável e com alta tecnologia. O sorgo contém 80-90\% do valor energético do milho (PERRY e CECAVA,1995), mas tem se constituído em boa alternativa em locais de solos pobres, sujeitos a veranicos ou próximos de centros urbanos.

Plantas de milho e sorgo, quando adequadamente ensiladas, são boas fontes de energia apresentando, contudo, níveis deficientes de nitrogênio, o que pode limitar a digestão microbiana no rúmen. Em levantamento feito por ROSTON e ANDRADE (1992), são citados valores médios de $7,0 \%$ de proteína bruta (PB) e $62,2 \%$ de nutrientes digestíveis totais (NDT) para silagens de milho e sorgo. Esta deficiência protéica é acentuada quando maiores taxas de ganho de peso são procuradas, com elevação da densidade energética da ração, por meio da complementação da dieta com alimentos concentrados.

A utilização de farelo ou tortas de oleaginosas como fonte protéica total ou parcial é prática comum na engorda de bovinos de corte. Estas fontes de proteína natural são insumos caros, podendo significar grande parcela no custo de alimentação de animais confinados.

Fontes de nitrogênio não-protéico (NNP), como a uréia, apresentam custos mais baixos, por unidade de nitrogênio, que as fontes de proteína verdadeira, mas tem seu uso limitado pela pouca aceitabilidade pelos animais e sua segregação, quando misturada com farelos, ou pela toxicidade, agravada pela elevada solubilidade no rúmen, o que a transforma muito rapidamente em amônia (SALMAN et al., 1996). Entretanto, quando adequadamente empregada, a uréia, associada a fontes de amido como os grãos de milho ou de sorgo, freqüentemente constitui-se na opção mais econômica na confecção de rações para novilhos em confinamento (FERREIRA et al., 1996), particularmente para animais mais velhos, que são relativamente menos exigentes em proteína, que animais mais novos. Por outro lado, SINDT et al. (1994) admitem que em dietas desta natureza a proteína não degradável no rúmen, juntamente com a proteína microbiana, pode não ser suficiente para atender as necessidades de animais jovens com elevada taxa de ganho de peso.

O presente trabalho teve como objetivos estudar aspectos produtivos de cultivares de milho e sorgo para produção de silagem e avaliar as silagens produzidas, associadas à torta de soja ou uréia no desempenho de bovinos de corte em confinamento.

\section{Material e Métodos}

O presente trabalho foi conduzido no Centro Nacional de Pesquisa de Gado de Corte (CNPGC) da Empresa Brasileira de Pesquisa Agropecuária (EMBRAPA) em Campo Grande, MS, em uma área de 15 ha de latossolo roxo. Foram avaliadas uma cultivar de milho (Zea mays L.) (AG 1051) e duas de sorgo (Sorghum bicolor, (L.) Moench), sendo uma granífera (BR 303) e a outra de duplo propósito (AG 2006).

Cerca de um terço da área foi cultivado com cada tipo de forrageira. O preparo do solo foi o convencional, com aração (arado de aiveca) e duas gradagens, e o plantio foi efetuado no período de 02 a 07/11/95, em linhas espaçadas de $0,80 \mathrm{~m}$. Nesta ocasião, foram aplicados $400 \mathrm{~kg} / \mathrm{ha}$ da formulação 05.25.25. Para o controle de invasoras foi utilizado atrazine + metalacloro (PRIMESTRA 6,5 1/ha). Em cobertura, 40 dias após o plantio, foram aplicados $120 \mathrm{~kg} /$ ha de uréia.

A distribuição das forrageiras na área foi feita em blocos ao acaso, com três repetições, de acordo com o gradiente de fertilidade do solo, em parcelas delimitadas por terraços.

As avaliações e amostragens foram feitas na época do corte para ensilagem (05/02/96 para o sorgo BR 303, 12/02/96 para o sorgo AG 2006 e 16/02/96 para o milho AG 1051). O número médio de plantas/ha foi estimado a partir do espaçamento entre linhas e do número médio de plantas/metro. O rendimento de matéria seca/ha foi estimado multiplicando-se o número médio de plan- 
tas/ha pelo peso médio de cada planta.

As medições, contagens e amostragens foram feitas em três locais dentro de cada parcela. Em cada local o espaçamento entre linhas foi determinado medindo-se a largura correspondente a 25 linhas. A trena estendida também serviu de referência para as demais observações: A medição da altura da planta foi efetuada na interseção da linha de planta com a trena; a contagem de plantas foi realizada em um metro linear, a partir da trena, em linhas alternadas em cada local em que a trena foi estendida. A amostragem de plantas foi feita cortando-se a $15 \mathrm{~cm}$ do solo todas as plantas contidas em meio metro linear, a partir da trena, em três posições. O número de plantas amostradas variou de 40 a 80 por parcela dependendo da forrageira.

As plantas amostradas foram utilizadas para avaliação do peso médio da planta e da proporção e peso médio dos componentes da planta.

Os dados foram analisados seguindo-se o modelo matemático: $\mathrm{Y}_{\mathrm{ij}}=\mu+\mathrm{C}_{\mathrm{i}}+\mathrm{B}_{\mathrm{j}}+$ eij sendo: $\mathrm{Y}_{\mathrm{ij}}=$ observações das variáveis (Produção de MS/ha de folhas, de colmos, de espigas/panículas e total) referentes à cultivar i do bloco $\mathrm{j} ; \mu=$ média geral; $\mathrm{C}_{\mathrm{i}}=$ efeito fixo da cultivar, sendo $i=$ sorgo AG 2006, sorgo BR 303 e millho AG 1051; $B_{j}=$ efeito de bloco, sendo $j=1,2$ ou 3 ; e $e_{i j}=$ erro associado a cada combinação $C_{i} \times B_{j}$.

Após as amostragens, cada forrageira foi armazenada em um silo do tipo trincheira e as silagens foram utilizadas em dois ensaios com animais confinados:

No primeiro ensaio (experimento 1) foram utilizados 72 bovinos F1 Pardo Suíço x Nelore, inteiros, com idade média de 20 meses e peso vivo médio inicial de $412 \mathrm{~kg}$. Foram avaliados nove tratamentos, em delineamento inteiramente casualizado, em desenho fatorial $3 \times 3$, sendo três tipos de silagem (milho AG 1051, sorgo granífero BR 303 e sorgo de duplo propósito AG 2006) e três níveis de substituição da proteína do farelo de soja pelo NNP da uréia (0; 50 e 100\%).

No segundo ensaio (experimento 2), foram utilizados 48 novilhos Nelore, com idade média de 34 meses e peso vivo médio inicial de $378 \mathrm{~kg}$, distribuídos em seis tratamentos, em delineamento inteiramente casualizado, em arranjo fatorial $2 \times 3$, envolvendo dois tipos de silagem (sorgo granífero BR 303 e sorgo de duplo propósito AG 2006) e três níveis de substituição da proteína do farelo de soja pelo NNP da uréia ( $0 ; 50$ e 100\%).

A composição dos concentrados com diferentes fontes de N, para ambos experimentos, é mostrada na Tabela 1. O cálculo das rações foi efetuado procurando-se suprir as necessidades de proteína degradável no rúmen (PDR), de acordo com o AFRC (1993), supondo-se consumo médio de MS de 2,4\% do PV. A dieta do animal foi constituída de silagem oferecida à vontade e concentrado fornecido na proporção de $0,72 \%$ do peso vivo com base na matéria seca (MS).

O período experimental compreendeu 22 dias de adaptação e 70 de coleta de dados, sendo dois períodos de 28 e um de 14 dias. Todas as pesagens foram realizadas antes dos animais receberem a primeira refeição.

O consumo de alimentos foi estimado em duas ocasiões, por meio de pesagens da quantidade oferecida e das sobras, durante quatro dias consecutivos. Nas mesmas épocas, foram coletadas amostras dos ingredientes do concentrado e das silagens para análises. Os teores de matéria seca (MS), proteína bruta (PB), nitrogênio amoniacal e o $\mathrm{pH}$ foram determinados segundo a metodologia descrita por SILVA (1990). A digestibilidade in vitro da matéria orgânica (DIVMO) foi determinada de acordo com a técnica de TILLEY e TERRY (1963) com algumas modificações no método de coleta do líquido ruminal e no processo de filtragem; a fibra em detergente neutro (FDN), segundo GOERING e VAN SOEST (1970), e a fibra em detergente ácido (FDA), de acordo com a ASSOCIATION OF OFFICIAL ANALYTICAL CHEMISTS (AOAC) 1980.

Os resultados do desempenho animal foram analisados por intermédio de um modelo matemático contendo os efeitos fixos de silagem e fonte protéica e a interação entre eles. O peso vivo inicial foi incluído no modelo como covariável. As forrageiras foram, ainda, comparadas por meio de estudos de contrastes. Também foram realizados estudos de regressão buscando-se avaliar o efeito da substituição do farelo de soja pela uréia no ganho de peso dos animais. Utilizou-se o procedimento GLM do SAS Institute (1990) para a identificação de diferenças significativas e, quando da existência das mesmas, as médias foram comparadas pelo teste Tukey a $5 \%$.

$\mathrm{O}$ custo das silagens não foi determinado. A análise econômica dos confinamentos foi feita considerando-se o preço de $\mathrm{R} \$ 20,00 / \mathrm{t}$ de silagem sugerido pelo ANUALPEC (1996). Os preços médios dos ingredientes do concentrados foram tirados da Revista Preços Agrícolas: ESALQ, v.10, n.117, julho/96. O custo com mão-de-obra foi o de dois operários rurais, por um período de 70 dias, recebendo dois salários mínimos por mês cada um, para 120 animais. Consideraram-se, ainda, combustível e lubrificantes para um trator na distribuição de ração e os custos com 
Rev. bras. zootec.

Tabela 1 - Composição química das dietas experimentais (\%MS)

Table 1 - Chemical composition of the experimental diets (\% DM)

\begin{tabular}{|c|c|c|c|c|c|c|}
\hline \multirow[t]{2}{*}{ Item } & \multicolumn{3}{|c|}{$\begin{array}{l}\text { Concentrado } \\
\text { Concentrate }\end{array}$} & \multicolumn{3}{|c|}{$\begin{array}{c}\text { Silagem } \\
\text { Silage }\end{array}$} \\
\hline & $\begin{array}{c}\text { FS } \\
S B M\end{array}$ & $\begin{array}{c}\mathrm{FS}+\mathrm{U} \\
S B M+U\end{array}$ & $\mathrm{U}$ & $\begin{array}{c}\text { Sorgo AG } \\
\text { Sorghum } A G\end{array}$ & $\begin{array}{c}\text { Sorgo BR } \\
\text { Sorghum BR }\end{array}$ & $\begin{array}{l}\text { Milho AG } \\
\text { Corn } A G\end{array}$ \\
\hline $\begin{array}{l}\text { Quirera de milho } \\
\text { Ground corn }\end{array}$ & 46,29 & 68,87 & 91,6 & - & - & - \\
\hline $\begin{array}{l}\text { Farelo de soja (FS) } \\
\text { Soybean meal (SBM) }\end{array}$ & 50,88 & 25,53 & - & - & - & - \\
\hline $\begin{array}{l}\text { Uréia(U) } \\
\text { Urea }\end{array}$ & - & 2,35 & 4,73 & - & - & - \\
\hline $\begin{array}{l}\text { Sulfato de amônio } \\
\text { Ammonia sulphate }\end{array}$ & - & 0,42 & 0,84 & - & - & - \\
\hline $\begin{array}{l}\text { Carbonato de cálcio } \\
\text { Limestone }\end{array}$ & 1,85 & 1,85 & 1,85 & - & - & - \\
\hline $\begin{array}{l}\text { Mistura mineral } \\
\text { Mineral mix }\end{array}$ & 0,92 & 0,92 & 0,92 & - & - & - \\
\hline $\begin{array}{l}\text { Monensina sódica } \\
\text { Monensin }\end{array}$ & 0,06 & 0,06 & 0,06 & - & - & - \\
\hline $\operatorname{MS}(D M)$ & 89,3 & 90,2 & 91,2 & 28,9 & 30,7 & 30,1 \\
\hline $\mathrm{pH}$ & - & - & - & 4,0 & 4,0 & 3,7 \\
\hline $\mathrm{PB}(C P)$ & 29,2 & 27,0 & 24,9 & 7,1 & 9,0 & 7,8 \\
\hline $\mathrm{PDR}^{1}(R D P)$ & 17,0 & 16,8 & 16,5 & 4,1 & 5,2 & 4,5 \\
\hline $\mathrm{EM}^{2}(M E)$ & 12,2 & 12,0 & 11,7 & 8,8 & 8,8 & 9,1 \\
\hline DIVMO (DOMD) & - & - & - & 58,9 & 58,5 & 60,6 \\
\hline FDA $(A D F)$ & - & - & - & 39,4 & 35,3 & 35,1 \\
\hline $\operatorname{FDN}(N D F)$ & - & - & - & 66,5 & 58,9 & 62,7 \\
\hline $\mathrm{N}^{-\mathrm{NH}_{3}}$ (\% of total $\left.N\right)$ & - & - & - & 10,8 & 11,0 & 7,0 \\
\hline
\end{tabular}

${ }^{1}$ Estimada conforme os coeficientes de degradabilidade do AFRC (1993).

${ }^{2}$ Estimada conforme WILSON e BRIGSTOCKE (1981): EM (MJ/kg) = DIVMO X 0,15.

${ }^{1}$ Estimated as the coefficients of degradability of AFRC (1993).

${ }^{2}$ Estimated as WILSON and BRIGSTOCKE (1981): ME (MJ/kg) $=.15$ DOMD\%

vacina e medicamentos com base nos preços de mercado de Campo Grande, MS. O juro sobre o capital foi de $2 \%$ ao mês por 70 dias. A amortização das instalações e dos equipamentos foi feita supondose vida útil de 10 anos e taxa de juros de $8 \%$ ao ano. A renda bruta foi calculada com base no peso da carcaça a um preço de $\mathrm{R} \$ 23,50$ a arroba.

\section{Resultados e Discussão}

Conforme mostrado na Tabela 2, o milho e o sorgo AG 2006 produziram plantas mais altas que o sorgo BR 303. Segundo CARVALHO (1995), a altura das plantas está diretamente relacionada com a fertilidade do solo, as condições climáticas, a época de plantio e o potencial genético de cada cultivar.

As produções de massa verde variaram de 31 a $35 \mathrm{t} / \mathrm{ha}$. Os rendimentos de matéria seca $(9,2$ a 11,2 $\mathrm{t} / \mathrm{ha})$ não diferiram estatisticamente $(\mathrm{P}>0,05)$ e foram semelhantes aos valores médios $(11,7$ para $\mathrm{o}$ sorgo e 10,7 t/ha para o milho) obtidos em levantamento realizado por DEMARCHI et al. (1995). Segundo ZAGO (1991), o potencial de produção de matéria seca aumenta com a altura da planta, entretanto, no presente experimento, o menor porte do sorgo granífero foi compensado pelo maior número de plantas/ha.

Do total de MS produzida pelo milho e pelo sorgo BR 303, mais de 50\% corresponderam à espiga ou panícula. Para o sorgo AG 2006, este valor correspondeu a $45 \%$, sendo a diferença compensada por maior proporção de colmos. A alta proporção de espigas observada na forragem de milho provavelmente foi favorecida pelo número de plantas/ha (47500), número abaixo das recomendações de MEDEIROS e VIANA (1980), mas que certamente reduziu a competição entre plantas.

DEMARCHI et al. (1995) citam vários autores que mostram que o valor nutritivo da silagem não está diretamente ligado ao conteúdo de grãos. Entretanto, de acordo com GOMIDE et al. (1987), a produção de espiga ou panículas é de grande importância, pois pode refletir diferenças de valor energético das silagens produzidas. Além disso, segundo NUSSIO (1993), a participação percentual de grãos na matéria seca total condiciona maior teor de MS à silagem produzi- 
SILVA et al.

Tabela 2 - Características produtivas dos sorgos AG 2006 e BR 303 e do milho AG 1051 no momento da ensilagem

Table 2 - Production characteristics of sorghum AG 2006, sorghum BR 303, and corn AG 1051 prior to ensiling

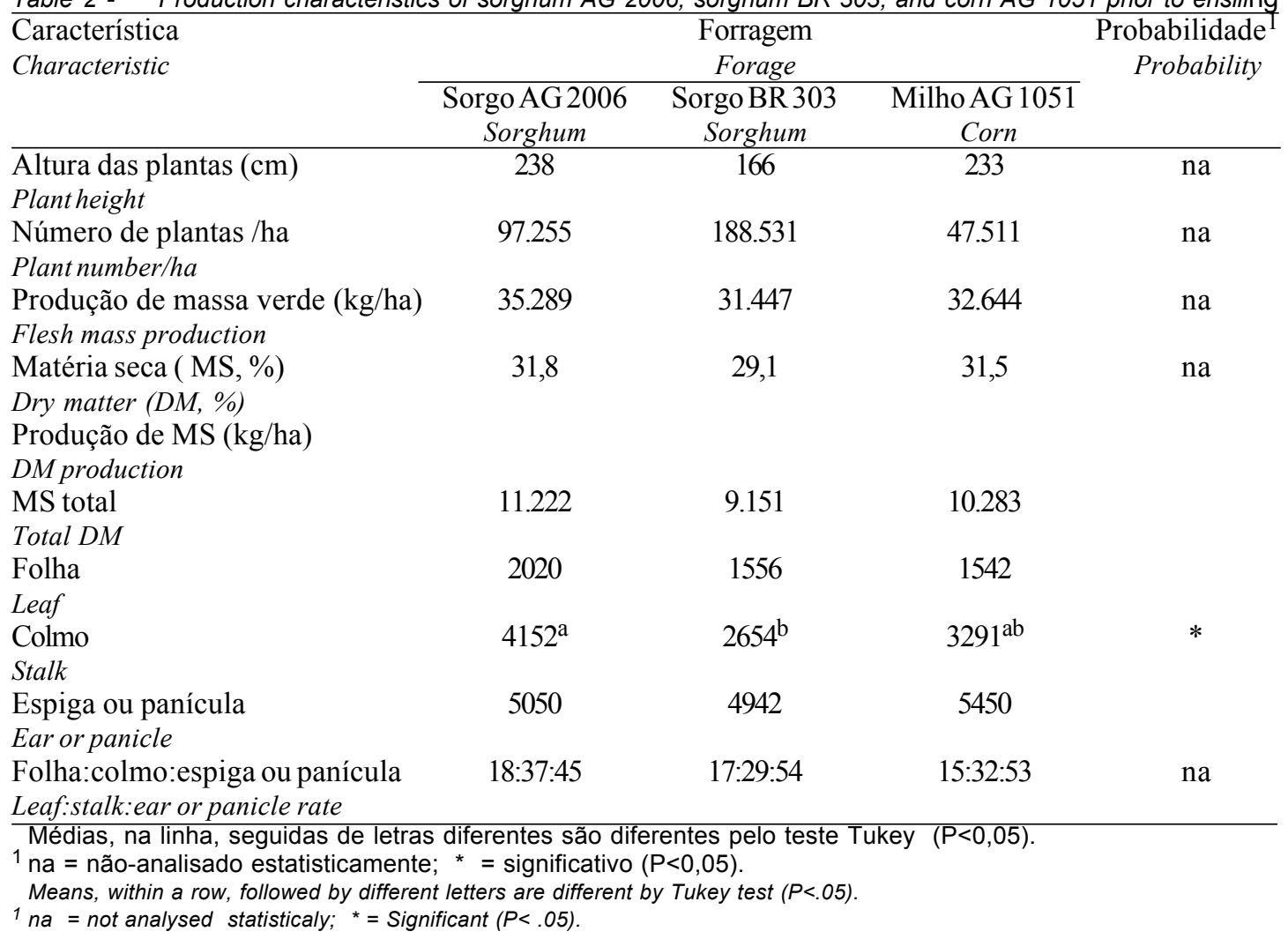

da. De acordo com esse autor, silagens com teores de MS mais elevados proporcionam maiores consumos de forragem em relação às silagens mais úmidas.

A qualidade das silagens produzidas foi avaliada com base nos parâmetros mostrados na Tabela 1. Os teores de matéria seca das silagens de milho e do sorgo AG 2006 obtidas indicaram que estas forrageiras foram cortadas pouco antes do ponto ideal de corte, de acordo com as recomendações de NUSSIO (1993), que sugere de 33 a $38 \%$ para o milho e 28 a $35 \%$ de MS para o sorgo. Em silagens de boa qualidade, o teor de amônia normalmente não ultrapassa $8 \%$ do $\mathrm{N}$ total e o $\mathrm{pH}$ deve ser igual ou inferior a 4,2 (SILVEIRA, 1988). As silagens de sorgo apresentaram teores de $\mathrm{N}$ amoniacal ligeiramente superiores ao nível acima mencionado indicando que houve, em pequena escala, algum tipo de fermentação indesejável. Os níveis de fibra foram maiores na silagem de sorgo AG 2006 provavelmente por causa da menor proporção panículas e da maior proporção de colmos desta forrageira. Os teores de PB variaram de 7,1 a 9,0\% e os coeficientes de digestibilidade in vitro da matéria orgânica (DIVMO), de 58,5 a 60,6\%, estando de acordo com os valores médios citados por ROSTON e ANDRADE (1992).
As estimativas de consumo e conversão alimentar dos animais mestiços (experimento 1) são apresentadas na Tabela 3. Os resultados, por representarem médias dos grupos dos animais, não permitiram análise estatística, mas pode-se observar que os consumos de MS, EM e outros nutrientes foram ligeiramente superiores com a silagem de milho e com o concentrado, cuja fonte de proteína era o farelo de soja.

Pode ser observado, ainda, que a conversão alimentar média do grupo de animais que recebeu silagem de milho foi melhor que a dos grupos que receberam silagem de sorgo, o mesmo acontecendo com os grupos que recebiam o farelo de soja. Isto pode ser explicado pela diferença de ganho de peso, que mostrou vantagem para a silagem de milho e o farelo de soja (Tabela 5).

Estes dados contrariam os resultados de FERREIRA et al. (1995), que encontraram maiores consumos de MS de silagens de sorgo granífero e sorgo de duplo propósito (10,4 a 10,6 kg/cab/dia) em relação à silagem de milho (9,3 a 9,5 kg/cab/dia).

A uréia, por ter sabor amargo, apresenta baixa aceitabilidade pelos animais, podendo interferir no consumo de alimentos. Quando se utiliza apenas a uréia como fonte suplementar de $\mathrm{N}$, geralmente o 
Rev. bras. zootec.

Tabela 3 - Consumo médio diário de MS (total e \% PV), MS da silagem, proteína (bruta-PB, degradável-PDR e metabolizável-PM), energia metabolizável (EM) e conversão alimentar (CA) de bovinos mestiços F1 Pardo Suíço x Nelore alimentados com diferentes silagens e suplementos protéicos

Table 3 - $\quad$ Average daily intake of DM (total and \% LW), silage DM, protein (crude, CP; rumen degradable, RDP and metabolizable, MP), metabolizable energy (ME) and feed:gain ratio (FG) of crossbred Brown Swiss $x$ Nellore bulls fed different silages and protein supplements

\begin{tabular}{|c|c|c|c|c|c|c|}
\hline \multirow[t]{2}{*}{ Item } & \multicolumn{3}{|c|}{$\begin{array}{c}\text { Silagem } \\
\text { Silage }\end{array}$} & \multicolumn{3}{|c|}{$\begin{array}{l}\text { Suplemento protéico } \\
\text { Protein supplement }\end{array}$} \\
\hline & $\begin{array}{l}\text { Sorgo AG } \\
\text { Sorghum }\end{array}$ & $\begin{array}{l}\text { Sorgo BR } \\
\text { Sorghum }\end{array}$ & $\begin{array}{l}\text { Milho } \\
\text { Corn }\end{array}$ & FS & $\mathrm{FS}+\mathrm{U}$ & $\mathrm{U}$ \\
\hline $\begin{array}{l}\text { MS total }(\mathrm{kg}) \\
\text { Total DM }\end{array}$ & 9,83 & 9,99 & 10,71 & 10,38 & 10,15 & 10,00 \\
\hline $\begin{array}{l}\mathrm{MS}(\% \mathrm{PV}) \\
D M(\% L W)\end{array}$ & 2,13 & 2,17 & 2,21 & 2,16 & 2,15 & 2,19 \\
\hline $\begin{array}{l}\text { Silagem }(\mathrm{kg}) \\
\text { Silage }\end{array}$ & 6,47 & 6,64 & 7,22 & 6,97 & 6,74 & 6,63 \\
\hline $\begin{array}{l}\mathrm{PB}(\mathrm{kg}) \\
C P\end{array}$ & 1,440 & 1,431 & 1,506 & 1,478 & 1,460 & 1,439 \\
\hline $\begin{array}{l}\mathrm{PDR}(\mathrm{kg}) \\
R D P\end{array}$ & 0,836 & 0,898 & 0,911 & 0,893 & 0,882 & 0,870 \\
\hline $\begin{array}{l}\mathrm{PM}(\mathrm{kg}) \\
M P\end{array}$ & 0,787 & 0,786 & 0,852 & 0,846 & 0,769 & 0,671 \\
\hline $\begin{array}{l}\mathrm{EM}(\mathrm{MJ}) \\
M E\end{array}$ & 97,91 & 97,59 & 107,61 & 102,82 & 100,88 & 99,41 \\
\hline $\begin{array}{l}\text { CA (kg MS/kg ganho PV) } \\
F: G \mathrm{~kg}(D M / \mathrm{kg} \text { gain } L W)\end{array}$ & 6,53 & 7,23 & 5,38 & 5,53 & 6,09 & 7,52 \\
\hline
\end{tabular}

Tabela 4 - Consumo médio diário por cabeça de MS (total e \% PV), de MS da silagem, proteína (bruta-PB, degradável-PDR e metabolizável - PM), energia metabolizável (EM) e conversão alimentar (CA) de novilhos Nelore alimentados com diferentes silagens e suplementos protéicos

Table 4 - Average daily intake of total DM (total and \%LW), silage DM, protein (crude, CP; rumen degradable, RDP and metabolizable, MP), metabolizable energy (ME) and feed:gain ratio (FE) of Nellore steers fed different silages and protein supplements

\begin{tabular}{|c|c|c|c|c|c|}
\hline \multirow[t]{2}{*}{ Item } & \multicolumn{2}{|c|}{$\begin{array}{c}\begin{array}{c}\text { Silagem } \\
\text { Silage }\end{array} \\
\end{array}$} & \multicolumn{3}{|c|}{$\begin{array}{c}\text { Suplemento protéico } \\
\text { Protein supplement }\end{array}$} \\
\hline & $\begin{array}{c}\text { Sorgo AG } \\
\text { Sorghum }\end{array}$ & $\begin{array}{c}\text { Sorgo BR } \\
\text { Sorghum }\end{array}$ & $\begin{array}{c}\mathrm{FS} \\
S B M\end{array}$ & $\begin{array}{c}\mathrm{FS}+\mathrm{U} \\
S B M+U\end{array}$ & $\mathrm{U}$ \\
\hline $\begin{array}{l}\text { MS total }(\mathrm{kg}) \\
\text { Total DM }\end{array}$ & 9,76 & 9,91 & 10,08 & 9,94 & 9,49 \\
\hline $\begin{array}{l}\mathrm{MS}, \% \mathrm{PV}(\mathrm{kg}) \\
D M, \% L W\end{array}$ & 2,30 & 2,33 & 2,35 & 2,33 & 2,26 \\
\hline $\begin{array}{l}\text { Silagem }(\mathrm{kg}) \\
\text { Silage }\end{array}$ & 6,66 & 6,82 & 7,00 & 6,84 & 6,38 \\
\hline $\begin{array}{l}\mathrm{PB}(\mathrm{kg}) \\
C P\end{array}$ & 1,378 & 1,383 & 1,396 & 1,389 & 1,357 \\
\hline $\begin{array}{l}\text { PDR }(\mathrm{kg}) \\
R D P\end{array}$ & 0,800 & 0,865 & 0,841 & 0,837 & 0,819 \\
\hline $\begin{array}{l}\mathrm{PM}(\mathrm{kg}) \\
M P\end{array}$ & 0,763 & 0,762 & 0,846 & 0,769 & 0,671 \\
\hline $\begin{array}{l}\mathrm{EM}, \mathrm{MJ}(\mathrm{kg}) \\
M E\end{array}$ & 96,44 & 96,17 & 98,37 & 97,24 & 93,31 \\
\hline $\begin{array}{l}\mathrm{CA}(\mathrm{kg} \mathrm{MS} / \mathrm{kg} \text { ganho PV) } \\
F: G(\mathrm{~kg} \mathrm{DM} / \mathrm{kg} \text { gain } L W)\end{array}$ & 7,35 & 7,44 & 7,31 & 7,22 & 7,65 \\
\hline
\end{tabular}


balanceamento só é obtido com níveis que podem comprometer o consumo total de MS. OBEID et al. (1980) observaram menor consumo de alimentos em dietas com altos níveis de uréia, particularmente quando o concentrado foi fornecido misturado à silagem, o mesmo não ocorrendo quando foi ministrado separadamente.

Não houve diferença entre as cultivares de sorgo quanto ao consumo médio de MS e outros nutrientes tanto para os animais mestiços como para os animais Nelore, sendo que a conversão alimentar média também não foi influenciada, conforme pode ser observado nas Tabelas 3 e 4 . Resultados semelhantes foram obtidos por FERREIRA et al. (1995), ao compararem silagens de sorgos graníferos e de duplo propósito.

Os consumos médios de MS no presente trabalho, em ambos experimentos, com animais mestiços inteiros $(2,1$ a $2,2 \%$ de PV) ou novilhos Nelore $(2,3 \%$ de PV) foram inferiores aos obtidos por FEIJÓ et al. (1996a) e FEIJÓ et al. (1996b) (2,4 a 2,7\% do PV), utilizando silagem de milho suplementada com vários níveis de concentrado e com novilhos dos mesmos grupos genéticos.

$\mathrm{Na}$ avaliação do desempenho animal, não houve interação $(\mathrm{P}>0,05)$ entre o tipo de silagem e a fonte protéica, para nenhuma das características avaliadas em ambos experimentos.

O desempenho dos animais mestiços é apresentado na Tabela 5. Observa-se que a silagem de milho foi superior $(\mathrm{P}<0,05)$ às silagens de sorgo para peso final, ganho de peso (total e diário) e peso da carcaça quente, sendo ainda superior à silagem de sorgo BR 303 quanto ao rendimento de carcaça. Não houve diferença entre as silagens de sorgo BR 303 e AG 2006.

De acordo com PERRY e CECAVA (1995), o valor nutricional da silagem de sorgo equivale a $80 \mathrm{a}$ $90 \%$ da silagem de milho. Os ganhos médios de peso obtidos com a silagem de sorgo foram de 70 a $77 \%$ dos obtidos com a silagem de milho. Os resultados encontrados contrariam informações de SILVA et al. (1991), no Rio Grande do Sul, cujos dados de

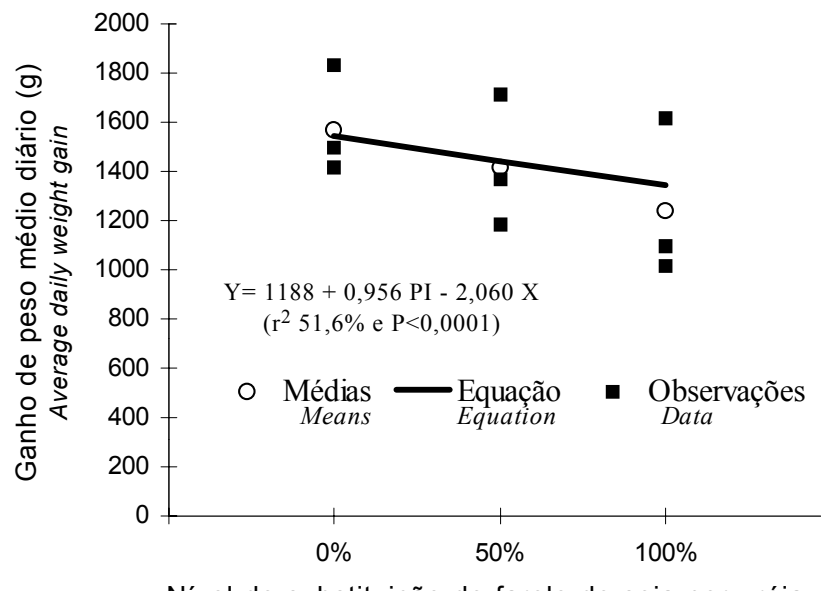

Nível de substituição do farelo de soja por uréia Level of substitution of soybean meal by urea

Figura 1 - Regressão do ganho de peso médio diário de bovinos mestiços F1 Pardo Suíço x Nelore, em relação ao nível de substituição de farelo de soja pela uréia.

Figure 1 - Regression of the average daily gain in crossbred F1 Brown Suiss $x$ Nellore bulls on the level of substitution of soybean meal by urea.

Tabela 5 - Pesos inicial e final, ganhos de peso total (GPV) e diário (GMD), peso (PCQ) e rendimento de carcaça de bovinos F1 Pardo Suíço x Nelore alimentados com diferentes silagens e suplementos protéicas

Table 5 - Initial and final weights, total weight (LWG) and daily gain (ADG), carcass weight (HCW) and dressing percentage of F1 Brown Swiss $x$ Nellore bulls fed different silages and protein supplements

\begin{tabular}{|c|c|c|c|c|c|c|}
\hline \multirow[t]{2}{*}{ Item } & \multicolumn{3}{|c|}{$\begin{array}{l}\text { Silagem } \\
\text { Silage }\end{array}$} & \multicolumn{3}{|c|}{$\begin{array}{l}\text { Suplemento protéico } \\
\text { Protein supplement }\end{array}$} \\
\hline & $\begin{array}{l}\text { Sorgo AG } \\
\text { Sorghum }\end{array}$ & $\begin{array}{l}\text { Sorgo BR } \\
\text { Sorghum }\end{array}$ & $\begin{array}{l}\text { Milho AG } \\
\text { Corn }\end{array}$ & $\begin{array}{c}\text { FS } \\
\text { SBM }\end{array}$ & $\begin{array}{c}\mathrm{FS}+\mathrm{U} \\
\mathrm{SBM}+\mathrm{U}\end{array}$ & $\mathrm{U}$ \\
\hline Peso inicial ajustado $(\mathrm{kg})$ & 412 & 412 & 412 & 412 & 412 & 412 \\
\hline $\begin{array}{l}\text { Adjusted initial weight } \\
\text { Peso final }(\mathrm{kg}) \\
\text { Final weight }\end{array}$ & $505^{\mathrm{b}}$ & $496^{\mathrm{b}}$ & $532^{\mathrm{a}}$ & 522 & 511 & 499 \\
\hline $\begin{array}{l}\text { GPV }(L W G), \mathrm{kg} \\
\text { GMD }(A D G), \mathrm{kg} \\
\text { PCQ }(H C W), \mathrm{kg} \\
\text { Rend. de carcaça (\%) }\end{array}$ & $\begin{array}{r}93^{\mathrm{b}} \\
1329^{\mathrm{b}} \\
269^{\mathrm{b}} \\
53,2^{\mathrm{ab}}\end{array}$ & $\begin{array}{r}84^{\mathrm{b}} \\
1200^{\mathrm{b}} \\
264^{\mathrm{b}} \\
53,1^{\mathrm{b}}\end{array}$ & $\begin{array}{r}120^{\mathrm{a}} \\
1714^{\mathrm{a}} \\
289^{\mathrm{a}} \\
54,3^{\mathrm{a}}\end{array}$ & $\begin{array}{r}110 \\
1571 \\
284^{\mathrm{a}} \\
54,3^{\mathrm{a}}\end{array}$ & $\begin{array}{r}99 \\
1414 \\
273^{\mathrm{b}} \\
53,4^{\mathrm{ab}}\end{array}$ & $\begin{array}{r}87 \\
1243 \\
265^{\mathrm{b}} \\
52,9^{\mathrm{b}}\end{array}$ \\
\hline
\end{tabular}

Dressing percentage

Médias, na linha, seguidas de letras diferentes, para cada fator, são diferentes $(P<0,05)$.

Means, within a row, followed by different letters for each factor are different $(P<.05)$. 
ganho de peso para silagens de milho e de sorgo duplo propósito foram superiores aos resultados com sorgo forrageiro, mas semelhantes entre si. FERREIRA et al. (1995), em Minas Gerais, também encontraram taxas semelhantes de ganho de peso para silagens de milho, sorgo granífero e sorgo duplo propósito, que foram superiores aos ganhos de peso com silagens de sorgo forrageiro e de capim elefante.

Os tratamentos que continham alimentos considerados de melhor qualidade (silagem de milho e o farelo de soja) provavelmente foram favorecidos pelas elevadas taxas de ganho de peso observadas, que são atribuídas, provavelmente, à ocorrência de crescimento compensatório. Os animais utilizados sofreram forte restrição alimentar, em pastagens de má qualidade, durante alguns meses antes do confinamento. VERDE (1974) cita vários autores que demonstram que, quanto mais alto o plano de nutrição no período de realimentação, maior e mais rápida será a recuperação do peso.

As taxas de ganho de peso apresentadas no presente trabalho, com animais de 20 meses, F1 Pardo Suiço x Nelore inteiros recebendo silagem de milho $(1,714 \mathrm{~kg} / \mathrm{dia})$, foram bastante superiores às mencionadas por FEIJÓ et al. (1996a), que utilizaram novilhos da mesma raça, mesma idade e com dietas semelhantes $(1,273 \mathrm{~kg} / \mathrm{dia})$.

$\mathrm{Na}$ Tabela 6 são mostrados os resultados referentes ao experimento 2, com novilhos Nelore, em que foram avaliadas apenas as silagens das duas cultivares de sorgo. Também, neste ensaio, não houve diferença entre as silagens de sorgo BR 303 e AG 2006 quanto ao desempenho dos animais. O peso vivo final médio foi de $450 \mathrm{~kg}$ e o ganho médio diário, de $1,028 \mathrm{~kg}$.

Utilizando-se análise de regressão para avaliar o efeito da substituição do farelo de soja pela uréia sobre o desempenho animal, pode-se observar que para os animais Nelore não houve diferença entre os níveis de substituição, com taxa média de ganho diário de 1,019 kg/cab (Tabela 6).

Para os animais mestiços, a equação de regressão obtida para ganho de peso foi $\hat{\mathrm{Y}}=1188+0,956$ PI - 2,060 X $\left(\mathrm{r}^{2}=51,6 \%\right.$ e $\left.\mathrm{P}<0,0001\right)$, sendo Y o ganho médio diário em gramas, PI o peso inicial (412 $\mathrm{kg}$ ) e X, o nível de substituição do farelo de soja por uréia, variável de 0 a 100\% (Figura 1).

Os dados médios de desempenho do experimento 1 são mostrados na Tabela 5. Observa-se que os grupos dos animais mestiços que receberam concentrados cuja fonte de $\mathrm{N}$ suplementar era o farelo de soja apresentaram melhor desempenho $(\mathrm{P}<0,05)$ do que os que receberam concentrados cuja fonte de $\mathrm{N}$ era a uréia, com resultado intermediário para o tratamento farelo de soja mais uréia.

Estes resultados estão coerentes com as observações de OBEID et al. (1980), que obtiveram taxas de ganho diário de $1,030 \mathrm{~kg}$ com o grão de soja e $0,800 \mathrm{~kg}$ com a uréia para animais Nelore inteiros. COUTINHO FILHO et al. (1995) também encontraram taxas de ganho de peso diferentes para o uso do farelo de algodão $(0,700 \mathrm{~kg} /$ dia $)$ e para a uréia $(0,600 \mathrm{~kg} /$ dia $)$ utilizando a cana de açúcar como volumoso.

Por outro lado, COUTINHO FILHO et al. (1987) não encontraram efeito da fonte de $\mathrm{N}$, ao compararem uréia, cama de frango, grão e farelo de soja, fornecidos para novilhos mestiços Canchim, com ganho médio de peso de $1,100 \mathrm{~kg} /$ dia. FERREIRA et al. (1996) obtiveram taxas de ganho de peso semelhantes entre o farelo de algodão, a uréia e o farelo de soja ( 1,2 a 1,3 kg/dia) com animais mestiços Holandês/zebu recebendo, ainda, silagem de milho mais cana de açúcar como volumoso.

Tabela 6 - Pesos inicial e final, ganhos de peso total (GPV) e diário (GMD) de novilhos Nelore alimentados com diferentes silagens e suplementos protéicos

Table 6 - Initial (IW) and final (FW) weights, average total (LWG) and daily gain (ADG) of Nellore steers fed different silages and protein supplements

\begin{tabular}{|c|c|c|c|c|c|}
\hline \multirow[t]{2}{*}{$\overline{\text { Item }}$} & \multicolumn{2}{|c|}{$\begin{array}{c}\text { Silagem } \\
\text { Silage }\end{array}$} & \multicolumn{3}{|c|}{$\begin{array}{c}\text { Fonte protéica } \\
\text { Protein supplement }\end{array}$} \\
\hline & $\begin{array}{l}\text { Sorgo AG } \\
\text { Sorghum }\end{array}$ & $\begin{array}{l}\text { Sorgo BR } \\
\text { Sorghum }\end{array}$ & $\begin{array}{l}\text { FS } \\
S B M\end{array}$ & $\begin{array}{l}\mathrm{FS}+\mathrm{U} \\
\mathrm{SBM}+\mathrm{U}\end{array}$ & $\mathrm{U}$ \\
\hline $\begin{array}{l}\text { Peso inicial }(\mathrm{kg}) \\
\text { Initial weight }\end{array}$ & 377 & 379 & 380 & 378 & 377 \\
\hline $\begin{array}{l}\text { Peso final }(\mathrm{kg}) \\
\text { Final weight }\end{array}$ & 450 & 450 & 453 & 450 & 446 \\
\hline $\begin{array}{l}\operatorname{GPV}(L W G),(\mathrm{kg}) \\
\mathrm{GMD}(A D G),(\mathrm{g})\end{array}$ & $\begin{array}{c}73 \\
1043 \\
\end{array}$ & $\begin{array}{c}71 \\
1014 \\
\end{array}$ & $\begin{array}{c}73 \\
1043 \\
\end{array}$ & $\begin{array}{c}72 \\
1029 \\
\end{array}$ & $\begin{array}{r}69 \\
986 \\
\end{array}$ \\
\hline
\end{tabular}


Os consumos de PDR (Tabela 3) foram ligeiramente superiores às necessidades, de acordo com as recomendações do AFRC (1993), porque o consumo total de MS observado (2,2\% do PV) foi menor que o utilizado para base de cálculo da ração (2,4\% do PV).

Diferenças no ganho de peso e na conversão alimentar, obtidas com os animais mestiços, não podem ser explicadas pelos consumos de PB e PDR, pois foram similares entre os tratamentos (Tabela 3 ). O consumo de proteína metabolizável (PM) foi maior nas rações que continham apenas o farelo de soja $(0,901 \mathrm{~kg} /$ dia $)$ em relação às dietas que continham apenas a uréia $(0,715 \mathrm{~kg} / \mathrm{dia})$. Com o tratamento farelo de soja mais uréia, obteve-se valor intermediário $(0,808 \mathrm{~kg} / \mathrm{dia})$.

As exigências em proteína metabolizável (PM) para manutenção e ganho de peso (equações 81 e 93), segundo o AFRC (1993), para bovinos inteiros de grande porte, com margem de segurança de $5 \%$, é de cerca de $0,660 \mathrm{~kg} / \mathrm{dia}$, considerando-se um animal de $450 \mathrm{~kg}$ de PV ganhando $1,750 \mathrm{~kg} / \mathrm{dia}$.

Aparentemente, as diferenças na performance dos animais com relação à fonte de $\mathrm{N}$ também não poderiam ser explicadas com base nos consumos de $\mathrm{PM}$, já que todos foram superiores à exigência total de PM calculada $(0,660 \mathrm{~kg} / \mathrm{dia})$.

Entretanto, WILKERSON et al. (1993) chamam atenção para possíveis fontes de erro com os métodos utilizados para estimar o consumo de PM. A proteína microbiana representa mais da metade da PM e é estimada com base na energia consumida que é fermentada no rúmen. Alguns fatores como a composição, forma física e consumo de matéria orgânica podem influir na fermentação ruminal. Além disso, eles citam vários autores que sugerem que carboidratos não-estruturais também deveriam ser considerados, além do consumo de energia, no cálculo da proteína microbiana produzida.

No presente trabalho, a quantidade de proteína microbiana pode ter sido superestimada nos tratamentos com $100 \%$ de uréia, visto que as dietas utilizadas continham alto conteúdo de volumoso (acima de $60 \%$ da MS), podendo ter ocorrido descompasso entre a disponibilidade de amônia e a degradabilidade

Tabela 7 - Planilha de custos e receitas dos animais F1 Pardo Suíço x Nelore em confinamento, alimentados com diferentes silagens e suplementos protéicos (R\$/cab.)

Table 7 - Cost and income and feedlot F1 Brown Swiss x Nellore animals fed different silages and protein supplements $(R \$ /$ head $)$

\begin{tabular}{|c|c|c|c|c|c|c|}
\hline \multirow[t]{2}{*}{ Item } & \multicolumn{3}{|c|}{$\begin{array}{l}\text { Silagem } \\
\text { Silage }\end{array}$} & \multicolumn{3}{|c|}{$\begin{array}{l}\text { Fonte protéica } \\
\text { Protein source }\end{array}$} \\
\hline & $\begin{array}{l}\text { Sorgo AG } \\
\text { Sorghum }\end{array}$ & $\begin{array}{l}\text { Sorgo BR } \\
\text { Sorghum }\end{array}$ & $\begin{array}{l}\text { Milho AG } \\
\text { Corn }\end{array}$ & $\begin{array}{c}\text { FS } \\
\text { SBM }\end{array}$ & $\begin{array}{l}\mathrm{FS}+\mathrm{U} \\
S B M+U\end{array}$ & $\mathrm{U}$ \\
\hline $\begin{array}{l}\text { Custo da ração } \\
\text { Feed cost }\end{array}$ & 76,84 & 75,62 & 80,82 & 88,60 & 77,69 & 66,99 \\
\hline $\begin{array}{l}\text { Boi magro, jun/96 } \\
\text { Thin cattle, Jun/96 }\end{array}$ & 270,00 & 270,00 & 270,00 & 270,00 & 270,00 & 270,00 \\
\hline $\begin{array}{l}\text { Mão-de-obra } \\
\text { Labour }\end{array}$ & 10,34 & 10,34 & 10,34 & 10,34 & 10,34 & 10,34 \\
\hline $\begin{array}{l}\text { Comb. e lubrificantes } \\
\text { Fuel and lubricant }\end{array}$ & 4,71 & 4,71 & 4,71 & 4,71 & 4,71 & 4,71 \\
\hline $\begin{array}{l}\text { Vacinas e outros } \\
\text { Vaccines and others }\end{array}$ & 0,98 & 0,98 & 0,98 & 0,98 & 0,98 & 0,98 \\
\hline $\begin{array}{l}\text { Investimento inicial } \\
\text { Inicial cost }\end{array}$ & 362,81 & 361,65 & 366,85 & 374,56 & 363,72 & 353,02 \\
\hline $\begin{array}{l}\text { Juros s/cap. inicial } \\
\text { Interest on investments }\end{array}$ & 17,78 & 17,72 & 17,98 & 18,36 & 17,82 & 17,30 \\
\hline $\begin{array}{l}\text { Depreciação } \\
\text { Depreciation }\end{array}$ & 12,16 & 12,16 & 12,16 & 12,16 & 12,16 & 12,16 \\
\hline $\begin{array}{l}\text { Custo final } \\
\text { Final cost }\end{array}$ & 392,81 & 391,53 & 396,99 & 405,15 & 393,70 & 382,48 \\
\hline $\begin{array}{l}\text { Receita bruta } \\
\text { Gross income }\end{array}$ & 416,73 & 412,03 & 457,47 & 447,02 & 426,22 & 410,99 \\
\hline $\begin{array}{l}\text { Receita líquida/Cab. } \\
\text { Net income/head }\end{array}$ & 23,92 & 20,51 & 60,48 & 41,88 & 34,52 & 28,51 \\
\hline
\end{tabular}


da fibra no rúmen. Além disso, HUBER (1984) ressalta a importância de que pode haver fatores contidos em fontes de proteína vegetal, essenciais aos micorganismos do rúmen e aos animais hospedeiros.

SINDT et al. (1994) concluíram que a uréia, como única fonte de $\mathrm{N}$, pode ser adequada para a engorda de bovinos jovens recebendo rações com altos níveis de carboidratos digestíveis. Para animais em crescimento, dietas com farelo de soja proporcionaram maiores taxas de ganho e maior eficiência de conversão, explicadas, segundo os autores, pelo melhor balanceamento de aminoácidos das dietas com farelo de soja. Os mesmos autores admitiram, ainda, que as exigências de PM calculadas poderiam estar subestimando as reais necessidades dos animais.

Fox et al. (1972), citados SINDT et al. (1994), sugerem que bovinos em crescimento compensatório pode ter maior exigência de proteína. Conforme mencionado anteriormente, os animais utilizados no experimento 1 passaram por forte restrição alimentar e tinham potencial para expressar ganho compensatório. As taxas de ganho de peso foram elevadas com o tratamento silagem de milho mais concentrado com farelo de soja, apresentando ganho médio de 1,8 kg/cab/dia.
Para os animais mestiços, as dietas que proporcionaram melhor desempenho animal foram, também, as que forneceram melhores resultados em termos econômicos (Tabela 7). Houve maior retorno/cabeça com o uso da silagem do milho AG 1051 (R\$ 60,48) com as duas silagens de sorgo, apresentando lucros semelhantes entre si ( $\mathrm{R} \$ 22,20$ em média). Com relação às fontes de $\mathrm{N}$, o maior retorno ocorreu com o uso de farelo de soja ( $\mathrm{R} \$ 41,88)$ seguido da mistura de farelo + uréia $(\mathrm{R} \$ 34,52)$ e da uréia $(\mathrm{R} \$ 28,51)$.

Para os novilhos Nelore, o retorno/cabeça foi semelhante para os dois tipos de silagem de sorgo (média de $\mathrm{R} \$ 10,00$ ). Quanto às fontes protéicas, o maior retorno/cabeça ocorreu com as dietas mais baratas: uréia $(\mathrm{R} \$ 16,91)$ seguida da mistura farelo de soja + uréia $(\mathrm{R} \$ 9,49)$ e pior retorno para o farelo de soja ( $\mathrm{R} \$ 3,80)$. Estes resultados econômicos refletem o pior desempenho animal (ganho de peso e conversão alimentar) dos novilhos Nelore de 34 meses, quando comparados aos animais mestiços de 20 meses e inteiros.

Com base em alguns trabalhos realizados em Minas Gerais, DUARTE et al. (1994) e VIANA et al. (1994) obtiveram maior retorno econômico com

\begin{tabular}{|c|c|c|c|c|c|}
\hline \multirow[t]{2}{*}{ Item } & \multicolumn{2}{|c|}{$\begin{array}{c}\text { Silagem } \\
\text { Silage }\end{array}$} & \multicolumn{3}{|c|}{$\begin{array}{l}\text { Fonte protéica } \\
\text { Protein supplement }\end{array}$} \\
\hline & $\begin{array}{l}\text { Sorgo AG } \\
\text { Sorghum }\end{array}$ & $\begin{array}{l}\text { Sorgo BR } \\
\text { Sorghum }\end{array}$ & $\begin{array}{c}\mathrm{FS} \\
S B M \\
\end{array}$ & $\begin{array}{l}\mathrm{FS}+\mathrm{U} \\
S B M+U\end{array}$ & $\bar{U}$ \\
\hline $\begin{array}{l}\text { Custo da ração } \\
\text { Feed cost }\end{array}$ & 74,15 & 72,88 & 83,48 & 74,06 & 63,02 \\
\hline $\begin{array}{l}\text { Boi magro jun/96 } \\
\text { Thin cattle, Jun/96 }\end{array}$ & 247,00 & 247,00 & 247,00 & 247,00 & 247,00 \\
\hline $\begin{array}{l}\text { Mão-de-obra } \\
\text { Labour }\end{array}$ & 10,34 & 10,34 & 10,34 & 10,34 & 10,34 \\
\hline $\begin{array}{l}\text { Comb. e lubrificantes } \\
\text { Fuel and lubricant }\end{array}$ & 4,71 & 4,71 & 4,71 & 4,71 & 4,71 \\
\hline $\begin{array}{l}\text { Vacinas e outros } \\
\text { Vaccines and others }\end{array}$ & 0,98 & 0,98 & 0,98 & 0,98 & 0,98 \\
\hline $\begin{array}{l}\text { Investimento inicial } \\
\text { Initial cost }\end{array}$ & 337,18 & 335,91 & 346,51 & 337,09 & 326,05 \\
\hline $\begin{array}{l}\text { Juros sem cap. inicial } \\
\text { Interest on investments }\end{array}$ & 16,52 & 16,46 & 16,98 & 16,52 & 15,98 \\
\hline $\begin{array}{l}\text { Depreciação } \\
\text { Depreciation }\end{array}$ & 12,13 & 12,13 & 12,13 & 12,13 & 12,13 \\
\hline $\begin{array}{l}\text { Custo final } \\
\text { Final cost }\end{array}$ & 365,87 & 364,53 & 375,65 & 365,77 & 354,19 \\
\hline $\begin{array}{l}\text { Receita bruta } \\
\text { Gross income }\end{array}$ & 374,99 & 375,55 & 379,44 & 375,28 & 371,10 \\
\hline $\begin{array}{l}\text { Receita líquida/Cab. } \\
\text { Net income/head }\end{array}$ & 9,12 & 11,02 & 3,80 & 9,50 & 16,91 \\
\hline
\end{tabular}


silagens de milho, de sorgo granífero e sorgo duplo propósito para engorda de novilhos confinados em relação à silagem de sorgo forrageiro.

PERRY e CECAVA (1995), concluíram que suplementos com combinação de NNP e proteína natural, geralmente, permitem desempenho adequado a um custo razoável para bovinos alimentados com dietas à base de silagem.

\section{Conclusões}

As três forrageiras avaliadas mostraram-se igualmente promissoras para a produção de silagem.

Silagem de milho e fontes de proteína verdadeira, como o farelo de soja, proporcionaram melhor desempenho na terminação, aos 24 meses, de bovinos mestiços não-castrados e podem proporcionar maior retorno econômico, dependendo da relação entre o custo dos insumos e o preço da carne.

As silagens produzidas com os sorgos BR $303 \mathrm{e}$ AG 2006 proporcionaram desempenho e retorno econômico semelhantes entre si para bovinos em confinamento.

Na terminação de novilhos Nelore aos 36 meses de idade, é recomendável o uso de uréia, em maior parte ou como fonte exclusiva de $\mathrm{N}$, quando associada ao grão de milho e à silagem de sorgo, pois é semelhante ao farelo de soja quanto ao desempenho animal e pode permitir maior retorno econômico.

\section{Agradecimentos}

Ao Grupo Hélio Coelho \& Filhos, de Campo Grande, MS, pela constante colaboração com a EMBRAPA Gado de Corte, a qual tornou possível a realização deste trabalho.

\section{Referências Bibliográficas}

AFRC. (England, UK). 1993. Energy and protein requirements of ruminants: An advisory manual prepared by the AFRC Tecnical Committee on responses of nutrientes. Wallingford: CAB Internacional. 159p.

ANUALPEC. 1996. São Paulo: FNP. 312p.

ASSOCIATION OF OFFICIAL ANALYTICAL CHEMISTS AOAC. 1980. Washington, D.C. p.1018.

CARVALHO, D.D. 1995. Competição de variedades de sorgo (Sorghum bicolor (L.) Moench) para produção de forragem para ensilagem. Bol. Ind. Anim., 52(2):33-138.

COUTINHO FILHO, J.L.V., PERES, R.M., JUSTO, C.L. et al. 1987. Diferentes fontes protéicas combinadas com espiga de sorgo na engorda de mestiços Canchim em confinamento. Bol. Ind. Anim., 44(2):203-220.

COUTINHO FILHO, J.L.V., SAMPAIO, A.A.M., EZEQUIEL, J.M.B. et al. 1995. Efeito de fontes de nitrogênio e da cobertura do cocho sobre o desempenho de bovinos confinados. R. Soc. Bras. Zootec., 24(3):363-370.

DEMARCHI, J.J.A. A., BOIN, C., BRAUN, G. 1995. A cultura do sorgo (Sorghum bicolor L. Moench) para a produção de silagens de alta qualidade. Zootecnia, 33(3):111-136.

DUARTE, J. de O., MONTEIRO, J.A., MIRANDA, J.E. et al. 1994. Custo de confinamento de bovinos com uso de materiais do CNPMS. In: CONGRESSO NACIONAL DE MILHO E SORGO, 20, 1994, Goiânia. Resumos... Goiânia: ABMS, p.273.

FEIJÓ, G.L.D., SILVA, J.M. da, THIAGO, L.R.L. de S. et al. Efeito de níveis de concentrado na engorda de bovinos confinados. Desempenho de novilhos F1 Pardo Suiço x Nelore. In: REUNIÃO ANUAL DA SOCIEDADE BRASILEIRA DE ZOOTECNIA, 33, 1996a. Fortaleza. Anais... Fortaleza: SBZ, 1996a, p.73-75.

FEIJÓ, G.L.D., SILVA, J.M. da, THIAGO, L.R.L. de S. et al. Efeito de níveis de concentrado na engorda de bovinos confinados. Desempenho de novilhos Nelore. In: REUNIÃO ANUAL DA SOCIEDADE BRASILEIRA DE ZOOTECNIA, 33, 1996b, Fortaleza. Anais... Fortaleza: SBZ, 1996b. p.70-72.

FERREIRA, J.J., VIANA, A.C., MIRANDA, J.E.C. et al. 1995. Efeito de silagens de milho, de sorgo e de capim elefante no desempenho de novilhos confinados. Sete Lagoas: EMBRAPA-CNPMS. 16p. (EMBRAPA-CNPMS. Boletim de Pesquisa, 2).

FERREIRA, J.J., SALGADO, J.G.F., CARNEIRO, J.C. Efeito de diferentes níveis de substituição de proteína por uréia na dieta de novilhos confinados. In: REUNIÃO ANUAL DA SOCIEDADE BRASILEIRA DE ZOOTECNIA, 33, 1996, Fortaleza. Anais... Fortaleza: SBZ, 1996. p.31-33.

GOERING, H.K., VAN SOEST, P. 1970. Forage fiber analyses (apparatus, reagents, procedures, and some applications). In: Agriculture Handbook n. 379. p.1-20.

GOMIDE, J.A., ZAGO, C.P., CRUZ, M.E. et al. 1987. Milho e sorgo em cultivos puros ou consorciados com soja, para produção de silagens. R. Soc. Bras. Zootec, 16(4):308-317.

HUBER, J.T. Uréia ao nível do rúmen. In: SIMPOSIO SOBRE NUTRIÇÃO DE BOVINOS: URÉIA PARA RUMINANTES. 4, 1984, Piracicaba. Anais... Piracicaba: FEALQ, 1984. p.6-24.

MEDEIROS, J.B., VIANA, A.C. 1980. Época, espaçamento e densidade de plantio para a cultura de milho. Milho: tecnologia garante produtividade e lucro. Inf. Agropec., 6(72):32-35.

NUSSIO, L.G. 1993. Milho e sorgo para a produção de silagem. In: PEIXOTO, A.M., MOURA, J.C., FARIA, V.P. (Eds.) Volumosos para bovinos. Piracicaba: FEALQ, p.75-177.

OBEID, J.A., GOMIDE, J.A., SILVA, J.F.C. 1980. Efeito de níveis de uréia e do manejo da alimentação sobre o consumo alimentar e o ganho de peso de novilhos zebu em confinamento. R. Soc. Bras. Zootec., 9(3):484-493.

PERRY, T.W., CECAVA, M.J. 1995. Beef cattle feeding and nutrition. 2. ed. San Diego: Academic Press. 387p.

ROSTON, A.J., ANDRADE, P. 1992. Digestibilidade de forrageiras com ruminantes: coletânea de informações. R. Soc. Bras. Zootec., 21(4)647-666.

SALMAN, A.K.D., MATARAZZO, S.V., EZEQUIEL, J.M.B. Estudo do balanço nitrogenado e da digestibilidade da matéria seca e da proteína de rações para ovinos suplementados com 
Rev. bras. zootec.

amiréia, uréia ou farelo de algodão. In: REUNIÃO ANUAL DA SOCIEDADE BRASILEIRA DE ZOOTECNIA, 33, Fortaleza, 1996. Anais... Fortaleza: SBZ, 1996. p.197-199.

SAS INSTITUTE (Cary, USA). SAS language reference. Cary, 1990. 1042p.

SILVA, D.J. 1990. Análise de alimentos (métodos químicos e biológicos). Viçosa: UFV, 166p.

SILVA, L.C.R., RESTLE, J., LUPATINI, G.C. Utilização de diferentes tipos de silagem como fontes de volumoso na terminação de novilhos em confinamento. In: REUNIÃO ANUAL DA SOCIEDADE BRASILEIRA DE ZOOTECNIA, 28, 1991, João Pessoa. Anais... João Pessoa: SBZ, 1991. p.278.

SILVEIRA, A.C. 1988. Produção e utilização de silagens. In: SEMANA DE ZOOTECNIA, 12, 1988, Pirassununga. Anais... Campinas: Fundação Cargill, p.119-134.

SINDT,M.H., STOCK, R.A., KLOPFENSTEIN, T. 1994. Urea vs. urea and escape protein for finishing calves and yearlings. Anim. Feed Sci. Tech., 49(1-2):103-117.

TILLEY, J.M.A., TERRY, R.A. 1963. A two-stage technique for the in vitro digestion of forage crops. J. Brit. Grassl. Soc., 18:104.

VERDE, L.S. 1974. Estado actual de los conocimientos sobre crecimiento compensatorio. Prod. Anim., 3:112-144.
VIANA, A.C., FERREIRA, J.J., MIRANDA, J.E.C. et al. 1994. Efeito de silagens de diferentes cultivares de milho, de sorgo e de capim elefante no desempenho de novilhos confinados. In: CONGRESSO NACIONAL DE MILHO E SORGO. 20., 1994, Goiânia. Resumos... Goiânia: ABMS, p.193.

WILKERSON, T.J., KLOPFENSTEIN, R.A., BRITTON, R.A. et al. 1993. Metabolizable protein and amino acid requirements of growing cattle. J. Anim. Sci., 71:2777-2784.

WILSON, P.N., BRIGSTOCKE, T.D.A. 1981. Improved feeding of cattle and sheep: A practical guide to modern concepts of ruminant nutrition. London: Granada. 238p.

ZAGO, C.P. Cultura de sorgo para produção de silagem de alto valor nutritivo. In: SIMPÓSIO SOBRE NUTRIÇÃO DE BOVINOS, 4, 1991, Piracicaba. Anais... Piracicaba: FEALQ, 1991. p.169-217.

Recebido em: 14/04/98

Aceito em: 26/11/98 